\title{
Rebonding of unused brackets with different orthodontic adhesives
}

Emigdio Enrique Orellana Jimenez ${ }^{1}$, Sérgio Paulo Hilgenberg², Márcia Cristina Rastelli³, Gibson Luiz Pilatti ${ }^{4}$, Bruno Orellana ${ }^{5}$, Ulisses Coelho ${ }^{6}$

Objective: To compare in vitro shear bond strength (SBS) of different orthodontic adhesives in bonding and repeatedly rebonding metal brackets, and to evaluate the bond failure site with the adhesive remnant index (ARI).

Methods: Specimens consisted of 90 extracted human first premolars, randomly divided into three groups $(n=30)$. The adhesives Alpha Plast (AP), Concise $^{\mathrm{TM}}(\mathrm{CO})$ and Transbond ${ }^{\mathrm{TM}} \mathrm{XT}(\mathrm{TB})$ were used in each group. Three SBS tests were performed, i.e., one at $\mathrm{T}_{0}$ (initial) and the other two at $\mathrm{T}_{1}$ and $\mathrm{T}_{2}$ (first and second rebondings, respectively), observing a 24-hour interval. The tests were performed in a Shimadzu AG-I (10kN) SBS testing machine, at a speed of $0.5 \mathrm{~mm} / \mathrm{min}$.

Results: SBS data were subjected to ANOVA, Tukey's test and Bonferroni test $(\mathrm{p}<0.05)$. For the ARI, the Kruskal Wallis test was performed, followed by the Dunn test. The results revealed that at $\mathrm{T}_{0}$ groups AP and CO showed SBS values that were near, but above TB values; and at $\mathrm{T}_{1}$ and $\mathrm{T}_{2}$, the highest $\mathrm{SBS}$ values were observed for the AP group, followed by the $\mathrm{CO}$ and $\mathrm{TB}$ groups.

Conclusion: Statistically significant differences were found in SBS between groups AP, CO and TB during bonding and repeated rebondings of unused metal brackets, with group AP achieving the highest SBS value. Regarding ARI, adhesive AP exhibited bond failure at the enamel-adhesive interface, with a higher enamel fracture frequency.

Keywords: Shear bond strength. Brackets. Orthodontic adhesives. Rebonding.

${ }^{1}$ Full Professor and MSc in Orthodontics, State University of Ponta Grossa (UEPG).

${ }^{2}$ MSc in Dentistry, UEPG.

${ }^{3}$ MSc in Dentistry, UEPG.

${ }^{4}$ Associate Professor, PhD, Periodontics, UEPG.

${ }^{5}$ Associate Professor, $\mathrm{PhD}$ in Orthodontics, Centro Paranaense University (UNICENTRO), Full Professor, PhD in Orthodontics - Center of Higher Education of Campos Gerais (CESCAGE)

${ }^{6}$ Associate Professor, PhD in Orthodontics, UEPG.
How to cite this article: Jimenez EEO, Hilgenberg SP, Rastelli MC, Pilatti GL, Orellana B, Coelho U. Rebonding of unused brackets with different orthodontic adhesives. Dental Press J Orthod. 2012 Mar-Apr;17(2):69-76.

Submitted: August 15, 2008 - Revised and accepted: March 2, 2009

» The authors report no commercial, proprietary, or financial interest in the products or companies described in this article.

Contact address: Emigdio Enrique Orellana Jimenez

R. Barão do Serro Azul, 275 - Centro - CEP: 84.010-210 - Ponta Grossa / PR - Brazil

E-mail: enriquejimenez@uol.com.br 


\section{INTRODUCTION}

Orthodontics has made significant improvements in recent decades with the use of new technologies that streamline orthodontic practice. The introduction of enamel acid etching ${ }^{1}$ fostered the development of the direct bonding technique, which is currently the method of choice for placement of orthodontic accessories. ${ }^{2}$

Despite significant advances in orthodontic adhesives in recent years, studies regarding bonding show that 5 to $10 \%$ of clinical bond failures occur in both self-curing and light-curing composite resins. ${ }^{2,3,4}$ Bracket bond and rebonding failures are now commonplace, which can result in treatment delays and increased cost of orthodontic treatment maintenance. ${ }^{4}$ Bond failures may occur due to chewing, bonding procedure deficiencies or little retention of some bracket bases. It occurs most frequently in mandibular second premolars. ${ }^{5}$

When bracket bond failure occurs, it can be handled in three different manners: 1) Rebonding the reconditioned bracket, 2) Bonding of an unused bracket, and 3) Using a bracket welded to an orthodontic band in cases of persistent bond failures. Studies show that rebonding an unused bracket provides greater SBS than rebonding a recycled bracket. ${ }^{6,78}$

Another aspect that has been addressed in different studies is the recycling of brackets, consisting of removal of the remaining adhesive from their base and reusing them. Bracket reuse, however, has been questioned in terms of biosafety and, from a mechanical standpoint, due to distortion of the bracket slot or base upon removal, which may result in (a) increased friction with orthodontic archwire, or (b) reduced adhesion, respectively. Furthermore, when rebonding brackets, unused or recycled, additional enamel loss may occur during debonding, on removal of adhesive remnant from the tooth surface, or during rebonding procedures. ${ }^{5,7}$

In assessing the rebonding of unused brackets, Bishara et al8 highlighted the effect of repeated rebonding on SBS in a sample of 15 extracted human molars using metal upper central incisor brackets (Victory Series ${ }^{\mathrm{TM}}$ - 3M). The brackets were bonded and rebonded with Transbond $^{\mathrm{TM}} \mathrm{XT}$ adhesive system (3M Unitek) three times using unused brackets. Bracket bonding involved $300 \mathrm{~g}$ of pressure prior to light-curing. Shearing test was performed with a Zwick mechanical testing machine at $5 \mathrm{~mm} / \mathrm{min}$ speed. In all trials, the brackets were debonded 30 minutes after bonding. ANOVA results for the three debonding times showed no significant difference between groups $(\mathrm{p}=0.104)$. However, when the total shearing load for each tooth was assessed between debonding sequences 1 and 3, ten teeth exhibited a significant SBS decrease $(\mathrm{p}=0.001)$ $(4.6 \pm 2.5 \mathrm{MPa})$, and five teeth showed significant increases $(2.8 \pm 1.6 \mathrm{MPa})$. These findings revealed that SBS may increase or decrease after second rebonding. Changes in SBS values may be related to changes observed in the morphological characteristics of each etched enamel surface due to adhesive remnant. The adhesive remnant index (ARI) showed no significant difference between the three groups.

Later, in 2002, Bishara et $\mathrm{al}^{9}$ evaluated the effect of bracket rebonding on the SBS of metal orthodontic brackets bonded and rebonded with two adhesive systems. Thirty-one freshly extracted human molars were used. Unused Victory Series ${ }^{\mathrm{TM}}$ maxillary central incisor brackets (3M) were employed in each bonding sequence. Group $1(n=15)$ was bonded with Transbond ${ }^{\mathrm{TM}}$ XT (3M) and Group $2(\mathrm{n}=16)$ with SmartBond (Gestenco). A Zwick mechanical testing machine was used at a speed of $5 \mathrm{~mm} / \mathrm{min}$. Results showed statistically significant differences. Transbond $^{\mathrm{TM}} \mathrm{XT}(4.4 \pm 2.3 \mathrm{MPa})$ showed a higher SBS than SmartBond $^{\mathrm{TM}}(2.2 \pm 2.6 \mathrm{MPa})$ in all tests. Overall, the teeth where brackets were rebonded had significantly lower SBS owing to the adhesive remnant on the enamel surface. The authors confirmed that changes in SBS may be related to changes in morphological characteristics of the enamel surface as a result of the presence of adhesive remnant.

The recent economic globalization has significantly reduced the costs of orthodontic accessories, leading orthodontists to rebond unused brackets instead of recycled brackets. Bonding a new bracket seems to be faster and less risky than reconditioning used brackets to bond them anew. The aim of this study, therefore, was to compare the in vitro shear bond strength (SBS), using human pre-molars, of different orthodontic adhesives in bonding and repeatedly rebonding unused metal brackets, thereby evaluating and comparing bond failure sites, for each of the tested adhesives, using the adhesive remnant index (ARI). 


\section{MATERIAL AND METHODS}

The research design was submitted to and approved by the Ethics Committee of the Ponta Grossa State University (COEP/UEPG) - Report \#40/2006, Protocol 06269/06.

This study used 90 extracted maxillary premolars - all extractions indicated for orthodontic purposes - of patients aged between 12 and 14 years old. With the aid of a stereomicroscope magnifier (8x), the teeth were selected based on the following criteria: Intact buccal surface, cracks free, caries, restorations or fractures and not having received any kind of pretreatment with chemical agents. Careful cleaning, storage and selection of teeth were meant to avoid changes that might jeopardize adhesion.

Morelli metal brackets specific for canines and premolars were used. The brackets had a base area of $13.02 \mathrm{~mm}^{2}$, and a $13.88 \mathrm{~mm}$ perimeter. These values were obtained automatically using the SolidWorks Software according to manufacturer instructions.

Ninety specimens were randomly divided into 3 groups ( $n=30)$, according to which composite resin was used: Group AP - Alpha Plast Orthodontic Adhesive (DFL), Group CO - Concise ${ }^{\mathrm{TM}}$ Orthodontic Adhesive (3M/ESPE), and Group TB - Transbond ${ }^{\mathrm{TM}} \mathrm{XT}$ (3M Unitek). A prototype device especially developed by the authors for the placement of accessories was used to position all brackets. A 3M Unitek universal positioner and a Morelli dynamometer were modified. With this modification a device was obtained (Fig 1) that positions the bracket and applies pressure evenly (300 grams), according to the method created by Bishara et al. ${ }^{8,9}$ Therefore, all brackets were bonded at a standard height of $4 \mathrm{~mm}$ and with a composite layer of uniform thickness. Before curing the material, all adhesive excess was removed with the aid of an explorer. All bonding procedures were performed by the same operator. After bonding, each specimen was stored for 24 hours in distilled water at room temperature in plastic containers with lids, separated and identified with specific numbering on the base of the PVC pipe according to each group, which were then subjected to mechanical shear tests. These tests followed the ISO/TR 11405 standard (2003) and were performed in a Shimadzu AG-I $(10 \mathrm{kN})$ testing machine at loading speed of $0.5 \mathrm{~mm} / \mathrm{min}$, and the breaking loads were recorded in Newtons and converted to megapascal. Three SBS tests were performed for each of the experimental groups at three different times, i.e., $\mathrm{T}_{0}$ (first bonding), $\mathrm{T}_{1}$ and $\mathrm{T}_{2}$, referring to the first and second rebonding, respectively. The interval between rebondings was 24 hours.

The adhesive remnant index (ARI) was observed with a stereomicroscope magnifier (Carl Zeiss, Brazil) with $8 \mathrm{X}$ magnification. The amount of adhesive remaining on the enamel after debonding was qualitatively assessed according to the scores used by Artun and Bergland. ${ }^{10}$ After recording the ARI at $\mathrm{T}_{0}$, the adhesive remnants were removed with a special carbide bur manufactured by TP Orthodontics, using high speed and water cooling. After every 10 specimens, a new bur was used to ensure consistent cutting. After recording the ARI at $\mathrm{T}_{1}$ and $\mathrm{T}_{2}$, the adhesive remnant removal procedure was repeated and observing a polished enamel surface prior to rebonding, thus completing the experiment. This methodology is simplified in Figure 2.

\section{RESULTS}

Table 1 presents the SBS values in MPa, with means and standard deviations for each experimental group under study.

The quantitative variable "shear bond strength" was evaluated taking into account the variation factor "experimental group", in a total of three groups: AP group, CO group and TB group, and time variation factor at 3 times $\left(\mathrm{T}_{0}\right.$ - bonding, $\mathrm{T}_{1}$ - first rebonding and $\mathrm{T} 2-$ second rebonding). According to the null hypothesis $\left(\mathrm{H}_{0}\right)$ the three materials tested at the 3 times should promote identical shear bond strength. Normal data distribution was confirmed

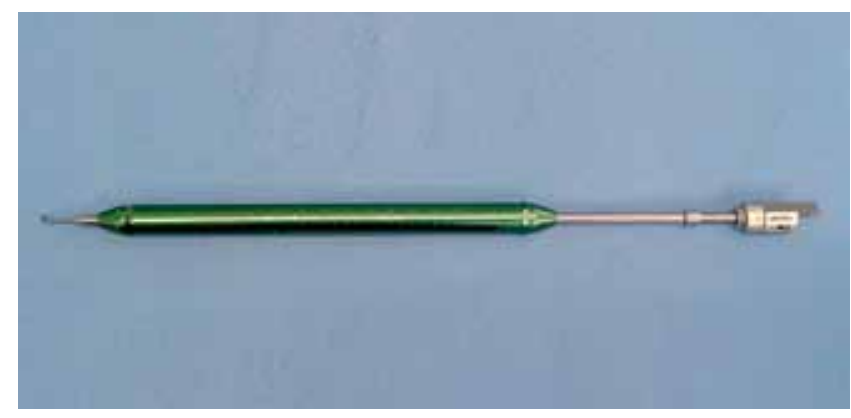

Figure 1 - Prototype of positioner modified by the authors. 


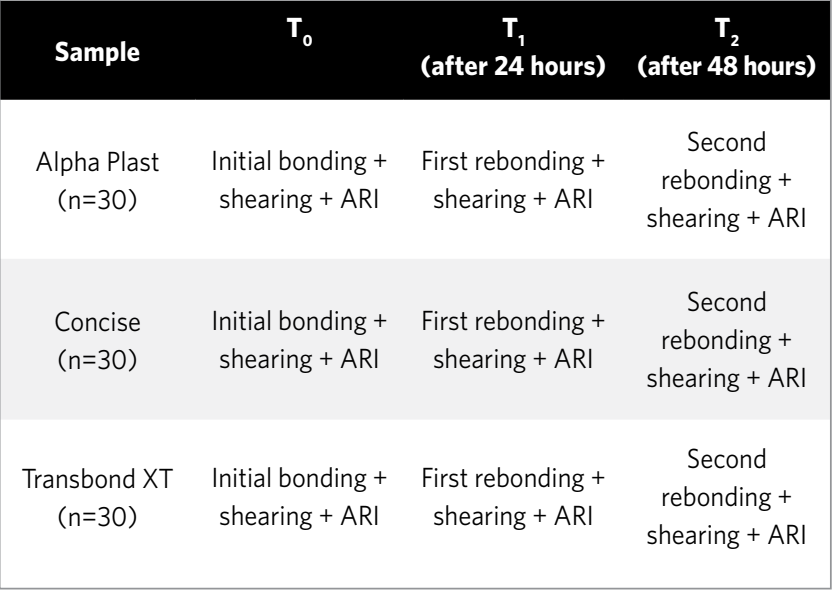

Figure 2 - Methodology applied to each group.

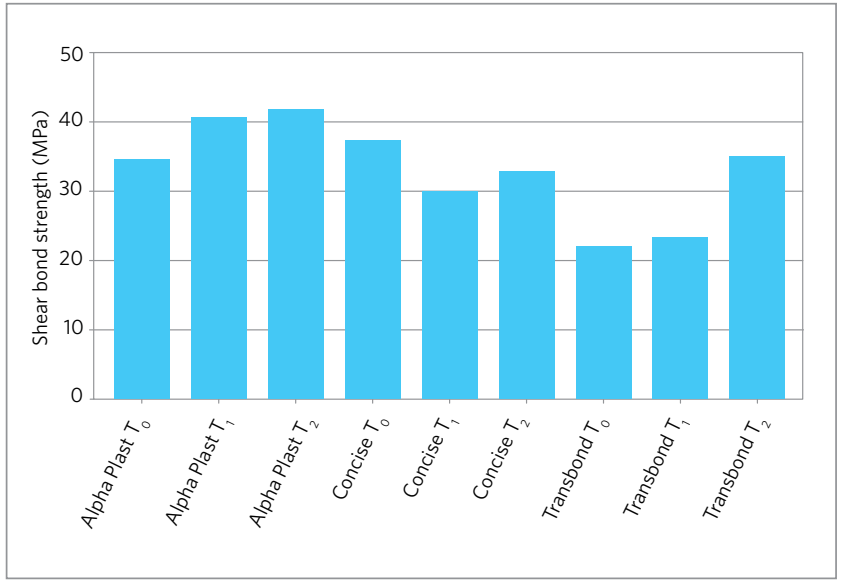

Figure 3 - Mean shear bond strength for each experimental group.

Table 1 - SBS values in MPa, means and standard deviations for each experimental group under study at $T_{0^{\prime}} T_{1}$ and $T_{2}$

\begin{tabular}{|c|c|c|c|c|c|c|c|c|c|}
\hline \multirow[b]{3}{*}{ Adhesive } & \multicolumn{3}{|c|}{$1^{\text {st }}$ Test - $T_{0}$} & \multicolumn{3}{|c|}{$2^{\text {nd }}$ Test $-T_{1}$} & \multicolumn{3}{|c|}{$3^{\text {rd }}$ Test - $T_{2}$} \\
\hline & \multicolumn{3}{|c|}{ Groups } & \multicolumn{3}{|c|}{ Groups } & \multicolumn{3}{|c|}{ Groups } \\
\hline & AP & $\mathrm{CO}$ & TB & AP & $\mathrm{CO}$ & TB & AP & $\mathrm{CO}$ & TB \\
\hline Mean & 34.18 & 36.74 & 22.83 & 40.28 & 29.43 & 23.20 & 40.71 & 32.48 & 25.85 \\
\hline s.d. & 13.50 & 11.25 & 7.10 & 11.21 & 6.54 & 7.19 & 8.74 & 7.79 & 19.17 \\
\hline
\end{tabular}

by the Kolmogorov Smirnov test, which allowed the parametric ANOVA test to be applied to two fixed criteria. Should the null hypothesis be rejected, the Tukey and Bonferroni (post hoc) tests for multiple comparisons would be applied.

Table 1 shows the mean values and standard deviations for shear bond strength (MPa) for each group and experimental period. With the exception of $\mathrm{T}_{0}$, when the specimens of groups AP and CO showed SBS values that were very near but higher than TB; the highest SBS values were observed in Group AP, followed by groups $\mathrm{CO}$ and $\mathrm{TB}$.

ANOVA showed that there was statistically significant difference in the group factor $(p<0.001)$; and for the interaction between the time and group factors, $(p=0.007)$. However, it did not show differences for the time factor $(\mathrm{p}=0.453)$.

By applying Tukey's multiple comparisons test for the group factor, it demonstrated that there were statistically significant differences between the three experimental groups, with the highest SBS values found in the AP group, followed by the CO group and TB group, which exhibited the lowest values for this variable. The data from these tests can be seen in Figure 4.

To assess the qualitative variable "Adhesive Remnant Index" (ARI) the nonparametric Kruskal Wallis test was applied. If the null hypothesis, according to which all groups would show equal ARI values, were to be rejected, the comparison between the mean positions of the samples would be performed using the Dunn test for multiple comparisons in order to detect between which groups existed statistically significant differences. For all tests, a 0.05 level of confidence was adopted. The tests were conducted with the aid of SPSS 13.0 software for Windows and Graphpad Instat version 3.05. The non-parametric Kruskal Wallis test was applied and 


\begin{tabular}{|cccccccc|}
\hline Test & Group & Versus group & $\begin{array}{c}\text { Difference } \\
\text { between means }\end{array}$ & Standard error & $\begin{array}{c}\text { Level of } \\
\text { significance }\end{array}$ & 95\% confidence interval \\
\hline & AP & CO & 4.4230 & 1.61479 & 0.018 & 0.6123 & 8.2336 \\
& AP & TB & 13.8099 & 1.59234 & 0.000 & 10.0522 & 17.5676 \\
\multirow{3}{*}{ Tukey } & CO & AP & -4.4230 & 1.61479 & 0.018 & -8.2336 & -.6123 \\
& CO & TB & 9.3869 & 1.52258 & 0.000 & 5.7939 & 12.9800 \\
& TB & AP & -13.8099 & 1.59234 & 0.000 & -17.5676 & -10.0522 \\
\end{tabular}

Figure 4 - Tukey's test for multiple comparisons for the group factor.

\begin{tabular}{|cccc|}
\hline Group & $\mathbf{n}$ & Median & Mean positions \\
\hline Alpha Plast $-\mathrm{T}_{0}$ & 30 & 0 & 60.76 \\
Concise $-\mathrm{T}_{0}$ & 30 & 1 & 82.60 \\
Transbond $-\mathrm{T}_{0}$ & 30 & 2 & 153.48 \\
Alpha Plast $-\mathrm{T}_{1}$ & 21 & 1 & 124.45 \\
Concise $-\mathrm{T}_{1}$ & 24 & 2 & 151.73 \\
Transbond $-\mathrm{T}_{1}$ & 26 & 1 & 126.17 \\
Alpha Plast $-\mathrm{T}_{2}$ & 15 & 1 & 100.40 \\
Concise $-\mathrm{T}_{2}$ & 24 & 1 & 82.16 \\
Transbond $-\mathrm{T}_{2}$ & 25 & 2 & 140.24 \\
\hline
\end{tabular}

Figure 5 - Frequency and median of values obtained for the Adhesive Remnant Index (ARI). yielded a value of $\mathrm{KW}=65.79$, with 8 degrees of freedom, considered statistically significant $(\mathrm{p}<0.0001)$. Thus, the null hypothesis (equal ARI for all groups) was rejected. Figure 5 shows the frequency and median of values obtained for ARI. The comparison between the sample mean positions was made by the Dunn multiple comparisons test, results can be seen in Tables 2 and 3. At $\mathrm{T}_{0}$ the ARI for Group TB was statistically higher than those of groups AP and $\mathrm{CO}(\mathrm{p}<0.05)$. There were no statistically significant differences between the groups at $\mathrm{T}_{1}$, whereas at $\mathrm{T}_{2}$, the ARI for group TB was statistically higher than that of group $\mathrm{C}(\mathrm{p}<0.05)$, with no difference between the other groups, as can be observed in Figure 6.

In analyzing the behavior of group AP at different times, a statistically significant difference was found only between $\mathrm{T}_{0}$ and $\mathrm{T}_{1}$, while for group $\mathrm{CO}$ statistically significant differences were detected between $\mathrm{T}_{0}$ and $\mathrm{T}_{1}$, and also between $\mathrm{T}_{1}$ and $\mathrm{T}_{2}$.

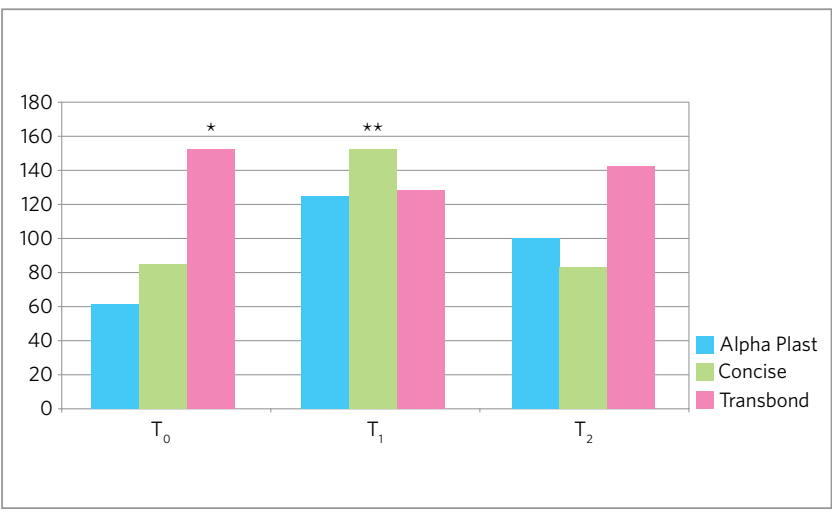

Figure 6 - Mean positions obtained for the Adhesive Remnant Index (ARI) for the Kruskal-Wallis test.

* Statistically significant difference $(p<0.05)$ found in comparing groups AP and $\mathrm{CO}$

* Statistically significant difference $(p<0.05)$ found when comparing to group $\mathrm{CO}$.

There was no statistically significant difference between periods $\mathrm{T}_{0}$ and $\mathrm{T}_{2}$, and between the three periods assessed for group TB.

\section{DISCUSSION}

Bracket bond failures are a frequent occurrence in orthodontic practice. It is jeopardizing as it results in increased treatment time and operating costs, requiring a greater number of appointments ${ }^{11}$ which can inconvenience the orthodontist and the patient alike. Identifying the cause of failure can help orthodontists reduce its occurrence, and instruct the patient on how to take proper care in order to avoid repeated bond failures and rebondings. ${ }^{12}$ It is also important to understand the bonding mechanism, that involve at least two interfaces: The enamel/adhesive interface and bracket/adhesive interface. ${ }^{2}$

When faced with the need to rebond metal brackets, several options are available: Using the 
Table 2 - Comparison between the mean positions by the Dunn multiple comparisons test.

\begin{tabular}{|c|c|c|c|c|c|c|}
\hline & \multicolumn{2}{|c|}{$T_{0} \times T_{1}$} & \multicolumn{2}{|c|}{$T_{0} \times T_{2}$} & \multicolumn{2}{|c|}{$T_{1} \times T_{2}$} \\
\hline & $\begin{array}{c}\text { Difference } \\
\text { between points }\end{array}$ & p value & $\begin{array}{c}\text { Difference } \\
\text { between points }\end{array}$ & p value & $\begin{array}{c}\text { Difference } \\
\text { between points }\end{array}$ & p value \\
\hline Alpha Plast & -63.686 & $p<0.01$ & -39.633 & $p>0.05 n s$ & 24.052 & $p>0.05 \mathrm{~ns}$ \\
\hline Concise & -69.129 & $p<0.01$ & 0.4333 & $p>0.05 n s$ & 69.536 & $p<0.01$ \\
\hline Transbond & 27.31 & $p>0.05 n s$ & 13.243 & $p>0.05 n s$ & -14.067 & $p>0.05 n s$ \\
\hline
\end{tabular}

Table 3 - Comparison between the mean positions by the Dunn multiple comparisons test.

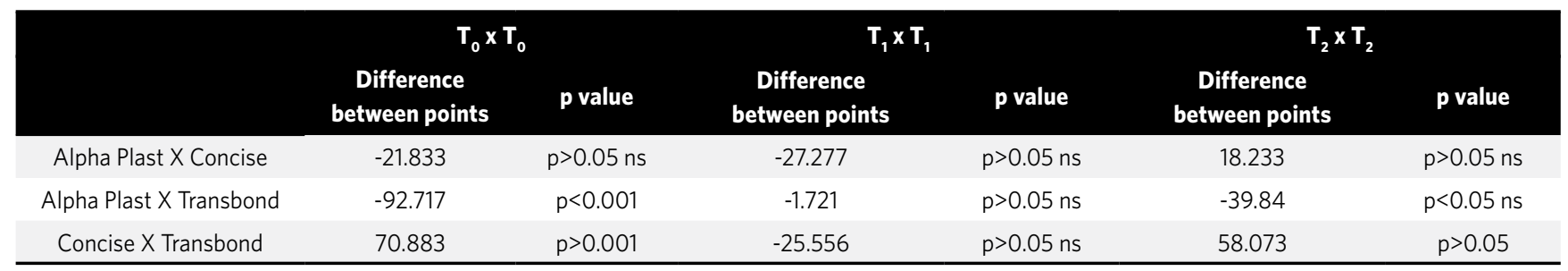

same bracket that suffered debonding, ${ }^{6,7,13-17}$ using thermocycled brackets, ${ }^{5,18}$ or sandblasted recycled brackets, ${ }^{19}$ with or without primer ${ }^{20,21}$ or using new brackets. ${ }^{8,9,19,22}$ This fact establishes the necessity of further scientific research in the pursuit of the most appropriate method.

In this study, shear bond strength (SBS) tests were employed by following the recommendations found in the articles reviewed in the literature ${ }^{5,8,9,14,16,21,22}$ with loading speed of $0.5 \mathrm{~mm} / \mathrm{min}$. (ISO TR 11405) provided by a mechanical testing machine Shimadzu AG-I with a 10kN load.

The most widely cited light-cured orthodontic adhesive in the literature was Transbond XT, which seems to be the "gold standard." It is a hybrid resin with a fair amount of filler. In this study, this adhesive achieved a shear bond strength (MPa) of 22.83 \pm 7.10 in initial bonding; $23.20 \pm 7.19$ in the first rebonding and $25.85 \pm 10.17$ in the second rebonding. These values are close to those reported by Mui et $\mathrm{al}^{7}$, Liu et al, ${ }^{23}$ Mondelli and Freitas ${ }^{17}$, and Pithon et al, ${ }^{21}$ who demonstrated Transbond XT's adequate adhesion to dental structure. These findings differ from the lower values found by Bishara et al ${ }^{8,9}$ due to the fact that the SBS reading was performed only 30 minutes after rebonding by these authors.

Concise Orthodontic Adhesive was cited in several studies. ${ }^{5,13,19,21}$ This adhesive contains $78 \%$ filler and is self-curing, for this reason it is the most often cited in studies assessing chemical-cured adhesives. In this study, this adhesive achieved a shear bond strength $(\mathrm{MPa})$ of $36.74 \pm 11.25$ at initial bonding $\left(\mathrm{T}_{0}\right) ; 29.43 \pm 6.54$ in the first rebonding $\left(\mathrm{T}_{1}\right)$ and $32.48 \pm 7.79$ in the second rebonding $\left(\mathrm{T}_{2}\right)$. These values are close to those reported by Francisconi et al, ${ }^{5}$ Quick et $\mathrm{al}^{19}$ and Pithon et $\mathrm{al}^{21}$ who demonstrated that this adhesive also features adequate adhesion to dental structure.

In this study of repeated rebondings, unused brackets were used, as this clinical procedure has been common practice for several decades and due to the fact that there are few such studies in the literature. ${ }^{8,9}$ It is likely that this is due to the fact that the reuse of debonded $^{6,7,13,14,19}$ and sandblasted ${ }^{15,24}$ brackets harks back to hard economic times when orthodontists used to import brackets and reuse meant cost reduction. 
But this is no longer true and bracket recycling can affect bonding quality, as shown by Dickinson and Pow$\operatorname{ers}^{25}$ as it deteriorates the bracket mesh base, thereby reducing shear bond strength (SBS).

SBS on rebonding remains controversial. In the view of some authors it is inferior to the first bonding ${ }^{20}$ whereas others argue that it is comparable to ${ }^{6}$ or even superior to the original bonding. ${ }^{9}$ This study involved unused brackets and found statistically significant differences in SBS between bonding $\left(\mathrm{T}_{0}\right)$ and the first rebonding $\left(\mathrm{T}_{1}\right)$ for the Alpha Plast group, whereas for the Concise group the difference was significant between $\mathrm{T}_{0}$ and $\mathrm{T}_{1}$ as well as $\mathrm{T}_{1}$ and $\mathrm{T}_{2}$. For the Transbond XT group, no statistically significant difference was found between the three periods, in disagreement with Wright and Powers ${ }^{26}$ who found no loss in the SBS properties of this adhesive.

The ARI index used in this study was consistent with the results reported in the work of Hirani and Sheriff ${ }^{20}$, which showed that the group bonded with Transbond XT had a score ranging between 1 and 2, in the same way, bondings made with Concise also had a score ranging between 1 and 2 . Bondings performed with the Alpha Plast showed that ARI scores were concentrated between 0 and 1 , indicating that part of the adhesive remained attached to the bracket and part to the tooth. However, this adhesive showed the greatest number of enamel fractures, compared with the other composite resins tested in this study.

The Alpha Plast adhesive system has seldom been used in laboratory experiments and was tested in this study because it is a self-curing adhesive widely used by orthodontists. It shows good bonding results as ascertained by the values achieved in the tests of this study, with values of $34.18 \pm 13.50$ MPa for initial bonding, $40.28 \pm 11.21$ in the first rebonding and $40.71 \pm 8.74$ in the second rebonding. These values are statistically superior to the results found for the Concise and Transbond XT adhesives. This superiority can be due to the finding reported by Dickinson and Powers ${ }^{25}$ namely, that composite resin filler content was shown in vitro to affect the adhesive force of brackets that rely on mechanical retention. Composites resins with a high amount of filler would provide improved adhesion to metal brackets when compared to low-filler composite resins. However, the elevated SBS of AP adhesive, caused a negative consequence of enamel fracture in most of the times, indicating the necessity of further studies by the manufacturer, in the attempt of keeping the adhesive properties while reducing biological consequences.

\section{CONCLUSIONS}

Given the methods used and results achieved in this in vitro study, it is reasonable to conclude that:

1 - There was a statistically significant difference in shear bond strength (MPa) between the Alpha Plast and Transbond XT groups, as well as between the Alpha Plast and Concise Orthodontic groups during bonding and repeated rebonding of new metal brackets.

2 - In rebonding with Transbond XT and Concise Orthodontic resins, bond failure sites are unpredictable, whereas with Alpha Plast bond failures occur predominantly at the enameladhesive interface, with higher frequency of dental enamel fractures. 


\section{REFERENCES}

1. Buonocore MG. A simple method of increasing the adhesion of acrylic filling materials to enamel surfaces. J Dent Res. 1955;34(6):849-53.

2. Ianni Filho D, Silva TBC, Simplício AHM, Lofredo LCM, Ribeiro RP. Avaliação in vitro da força de adesão de materiais de colagem em Ortodontia: ensaios mecânicos de cisalhamento. Rev Dental Press Ortod Ortop Facial. 2004;9(1):39-48

3. Zachrisson BU. Clinical experience with direct bonded orthodontic retainers. Am J Orthod. 1977;71(4):440-8.

4. Chamda RA, Stein E. Time-related bond strengths of light-cured and chemically cured bonding systems: an in vitro study. Am J Orthod Dentofacial Orthop. 1996;110(4):378-82

5. Francisconi PAS, Souza CS, Scucuglia LR, Rosa HM. Influência da termociclagem na análise da resistência ao cisalhamento do cimento de ionômero de vidro (Fuji Ortho LC) e da resina composta (Concise Ortodôntico), utilizados na colagem de braquetes ortodônticos. Rev FOB. 2000;8(3-4):9-14.

6. Egan FR, Alexander AS, Cartwright GE. Bond strength of rebonded orthodontic brackets. Am J Orthod Dentofacial Orthop. 1996;109(1):64-70.

7. Mui B, Rossouw PE, Kulkarni GV. Optimization of procedure for rebonding dislodged orthodontic brackets. Angle Orthod. 1999;69(3):276-81.

8. Bishara SE, VonWald L, Laffoon JF, Warren JJ. The effect of repeated bonding on the shear bond strength of a composite resin orthodontic adhesive. Angle Orthod. 2000;70(6):435-41.

9. Bishara SE, Laffoon JF, Vonwald L, Warren JJ. The effect of repeated bonding on the shear bond strength of different orthodontic adhesives. Am J Orthod Dentofacial Orthop. 2002;121(5):521-5.

10. Artun J, Bergland S. Clinical trials with crystal growth conditioning as an alternative to acid-etch enamel pretreatment. Am J Orthod Dentofacial Orthop. 1984;85(4):333-40

11. Pinto AS, Pinto LAMS, Cilense M, Melo ACM, Terra AMV. A reciclagem de braquetes na clínica ortodôntica. Ortodontia. 1996;29(2):63-7.

12. Powers JM, Kim HB, Turner DS. Orthodontic adhesives and bond strength testing. Semin Orthod. 1997:3(3):147-56.

13. Penido SMMO, Martins JCR. Avaliação da resistência ao cisalhamento de braquetes reciclados e novos recolados. Rev Dental Press Ortod Ortop Facial. 1998;3(6):45-52
14. Tavares SW, Consani S, Nouer D, Magnani MBBA, Pereira Neto JS, Romano F. Evaluation in vitro of the shear bond strength of aluminum oxide recycled brackets. Braz J Oral Sci. 2003;2(7):378-81.

15. Eminkahyagil N, Arman A, Cetinsahin A, Karabulut E. Effect of resin-removal methods on enamel and shear bond strength of rebonded brackets. Angle Orthod. 2006;76(2):314-21.

16. Pithon MM, Santos RL, Oliveira MV, Ruellas AC, Romano FL. Metallic brackets bonded with resin-reinforced glass ionomer cements under different enamel conditions. Angle Orthod. 2006;76(4):700-4.

17. Mondelli AL, Freitas MR. Estudo comparativo da resistência adesiva da interface resina/braquete, sob esforços de cisalhamento, empregando três resinas compostas e três tipos de tratamento na base do braquete. Rev Dental Press Ortod Ortop Facial. 2007;12(3):111-25.

18. Harari D, Gillis I, Redlich M. Shear bond strength of a new dental adhesive used to bond brackets to unetched enamel. Eur J Orthod. 2002;24(5):519-23.

19. Quick AN, Harris AM, Joseph VP. Office reconditioning of stainless steel orthodontic attachments. Eur J Orthod. 2005;27(3):231-6.

20. Hirani $S$, Sherriff M. Bonding characteristics of a self-etching primer and precoated brackets: an in vitro study. Eur J Orthod. 2006;28(4):400-4.

21. Pithon MM, Oliveira MV, Ruellas ACO, Romano FL. Shear bond strength of orthodontic brackets to enamel under different surface treatment conditions. J Appl Oral Sci. 2007;15(2):127-30

22. Chung $\mathrm{CH}$, Friedman SD, Mante FK. Shear bond strength of rebonded mechanically retentive ceramic brackets. Am J Orthod Dentofacial Orthop. 2002;122(3):282-7.

23. Liu JK, Chung $\mathrm{CH}$, Chang CY, Shieh DB. Bond strength and debonding characteristics of a new ceramic bracket. Am J Orthod Dentofacial Orthop. 2005;128(6):761-5.

24. Tavares SW, Consani S, Nouer DF, Magnani MBBA, Nouer PRA, Martins LM Shear bond strength of new and recycled brackets to enamel. Braz Dent J. 2006;17(1):44-8.

25. Dickinson PT, Powers JM. Evaluation of fourteen direct-bonding orthodontic bases. Am J Orthod. 1985;78(6):630-9.

26. Wright LW, Powers JM. In vitro tensile bond strength of reconditioned brackets. Am J Orthod. 1985;87:247-52. 